\title{
The vertical heterogeneity of soil detachment by overland flow on the water-level fluctuation zone slope in the Three Gorges Reservoir, China
}

\author{
Ping Guo ${ }^{1}$, Hai Xiao ${ }^{1}$, Feng Gao ${ }^{1}$, Zijuan $\mathrm{Li}^{1}$, Huan $\mathrm{Hu}^{1}$, Qianheng Zhang ${ }^{1}$, Zhenyao Xia ${ }^{1}$, \\ Mingyi $\mathrm{Li}^{1}$, and Yueshu Yang ${ }^{1}$ \\ ${ }^{1}$ China Three Gorges University
}

March 15, 2021

\begin{abstract}
Submersion and exposure from the operation of the Three Gorges Reservoir (TGR) can alter soil properties and plant characteristics at different elevations of the water level fluctuation zone (WLFZ), possibly influencing soil detachment capacity (Dc), but the vertical heterogeneity of this effect is uncertain. Soil samples were taken from 6 segments (5 m elevation per segment) along a slope profile in the WLFZ of the TGR to clarify the vertical heterogeneity of Dc. Scouring experiments were conducted at 5 slope gradients $(17.63 \%, 26.79 \%, 36.40 \%, 46.63 \%$, and $57.74 \%)$ and 5 flow rates $(10,15,20,25$, and $30 \mathrm{~L}$ min-1) to determine Dc. The results indicate that the soil properties and biomass parameters of the WLFZ are strongly affected by elevation. Dc fluctuates with increasing elevation, with maximum and minimum average values at elevations of 145-150 m and 165-170 $\mathrm{m}$, respectively. Linear equations accurately describe the relationships between Dc and hydrodynamic parameters. $\tau$, $\omega$, and E perform much better than U. Furthermore, a clear improvement is seen when using the general index of flow intensity to estimate Dc. Dc is significantly negatively correlated with MWD $(\mathrm{p}<0.05)$ and organic matter $(\mathrm{p}<0.01)$ but not significantly correlated with other soil properties $(\mathrm{p}>0.05)$. At elevations of 145-150 m and 170-175 m, rill erodibility was greater than at other elevations. The critical hydraulic parameters were highest in the $165-170 \mathrm{~m}$ segments, both showing obviously fluctuation in the vertical direction of slope surface. This research highlighted the vertical heterogeneity of the soil detachment and was helpful to understand the mechanisms of soil detachment processes in the WLFZ of the TGR.
\end{abstract}

\section{Hosted file}

Manuscript.pdf available at https://authorea.com/users/340153/articles/513619-the-verticalheterogeneity-of-soil-detachment-by-overland-flow-on-the-water-level-fluctuation-zoneslope-in-the-three-gorges-reservoir-china 

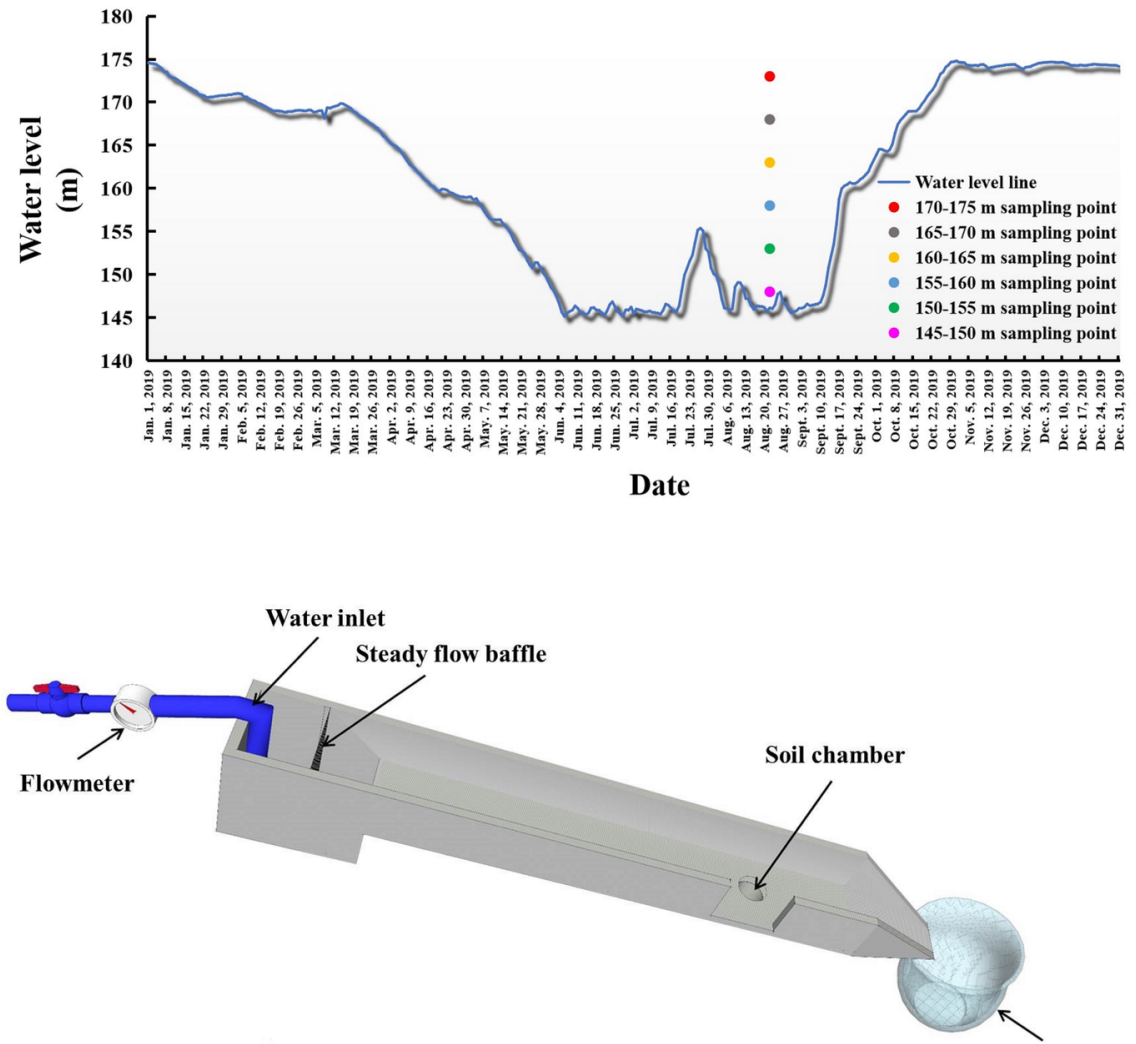

Collecting bucket 


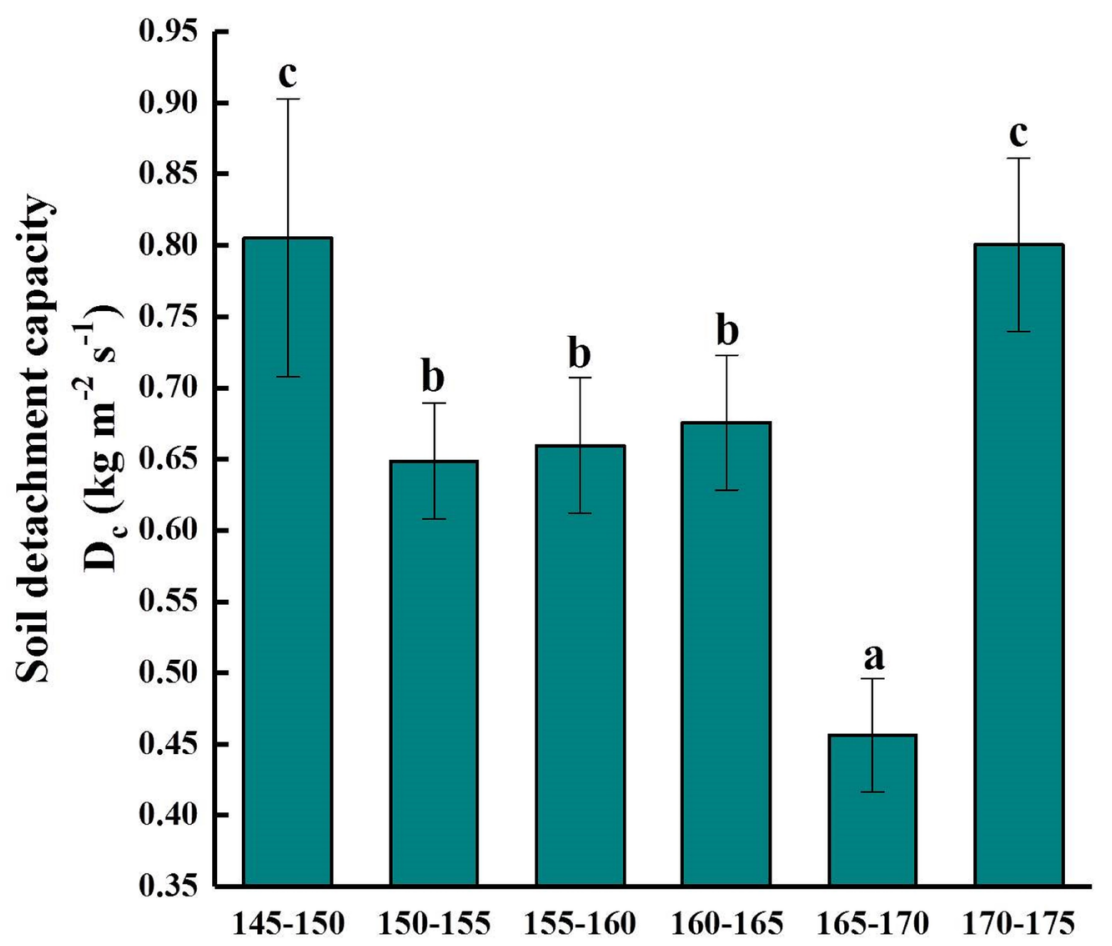

Elevation

(m)
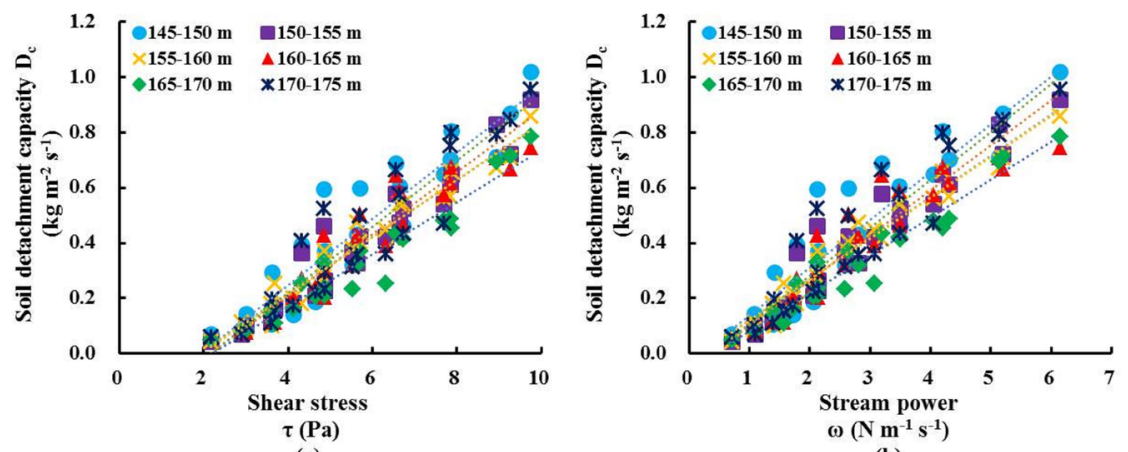

(a)

(b)

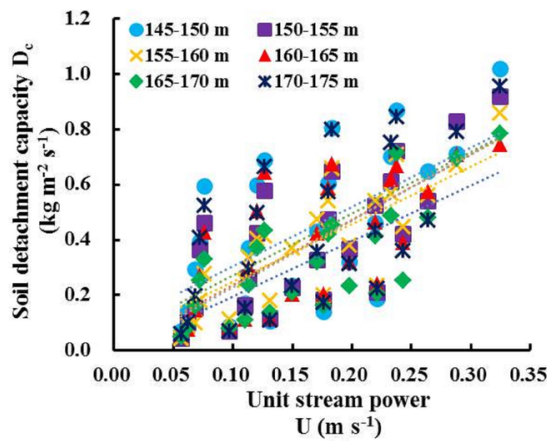

(c)

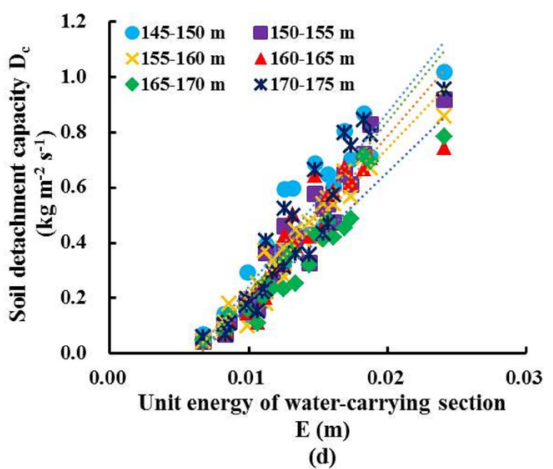




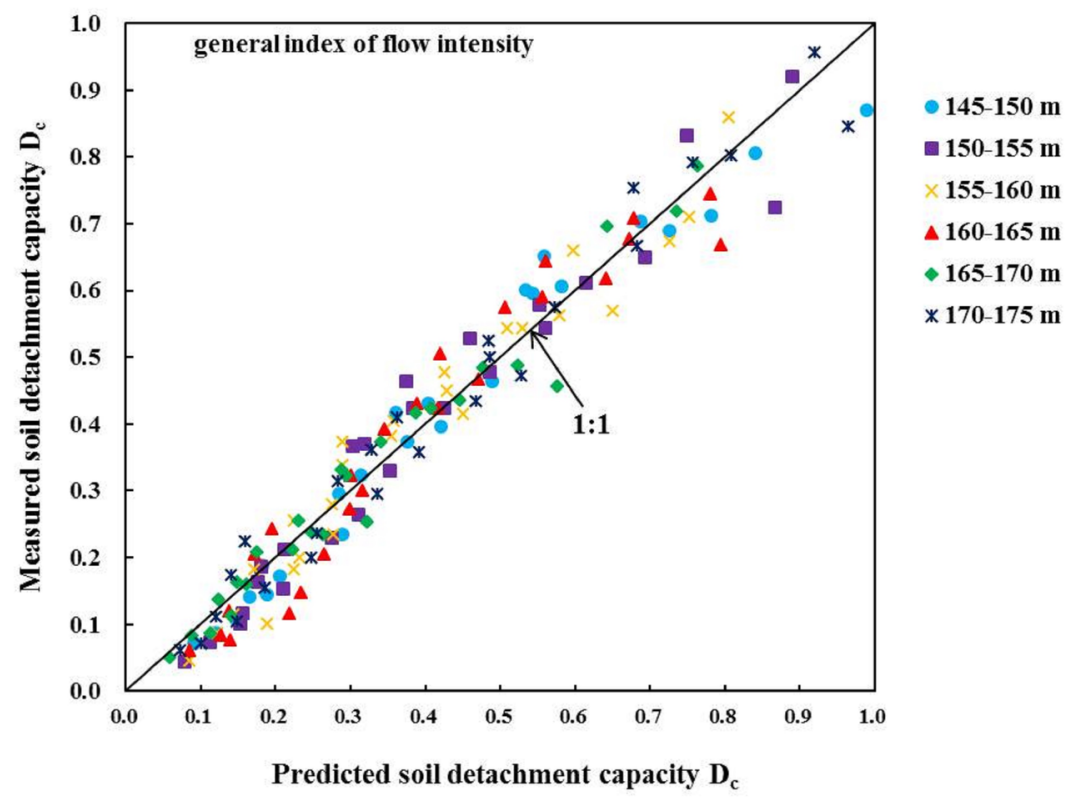

